\title{
A pantomima de Regina: fragmento simbólico integrado à rede interdiscursiva de reciclagem memorialística
}

\author{
Daiman Oliveira da Costa*
}

\begin{abstract}
Resumo
Este artigo se propõe a analisar um pontual acontecimento discursivo presente na entrevista de Regina Duarte, ex-secretária especial de cultura do governo brasileiro, para a emissora de televisão CNN Brasil, em 7 de maio de 2020. Mais especificamente, defende-se a hipótese de que a marchinha "Pra frente, Brasil", cantada por Regina durante a entrevista, funcionou como um acontecimento discursivo sutilmente integrado a uma rede interdiscursiva que, no Brasil, continuamente reforça simbólicas reciclagens da memória histórica referente ao período da Ditadura Militar (1964-1985) por meio da atualização da memória discursiva. Para tanto, a partir de conceitos-chave dentro do quadro teórico-metodológico da Análise do Discurso francesa, desenvolve-se um percurso conceitual pautado, sobretudo, nas noções de memória histórica, memória discursiva, interdiscurso e pré-discurso.

Palavras-chave: Memória histórica. Memória discursiva. Interdiscurso. Prédiscurso.
\end{abstract}

\footnotetext{
* Doutorando em Linguística e Língua Portuguesa pelo Programa de Pós-Graduação em Letras da Pontifícia Universidade Católica de Minas Gerais (PUC Minas). Mestre em Estudos da Linguagem pelo Programa de Pós-Graduação em Letras da Universidade Federal de Ouro Preto (UFOP). Bolsista da Coordenação de Aperfeiçoamento de Pessoal de Nível Superior (CAPES). ORCID: https://orcid.org/0000-0002-6258-764X
}

Cadernos CESPUC de Pesquisa. Série Ensaios. n.37, $2^{\circ}$ Sem./2020, p. 126-146. e-ISSN: 2358-3231 (OJS). Recebido em: 16/09/2020. Aceito em: 19/10/2020. 


\title{
Regina's Pantomime: Symbolic Fragment Integrated Into The Interdiscursive Network of Memorial Recycling
}

\author{
Daiman Oliveira da Costa
}

\begin{abstract}
This paper proposes to analyze a specific discursive event present in the interview of Regina Duarte, former special secretary of culture of the Brazilian government, to the television station CNN Brasil, on May 7, 2020. More specifically, the hypothesis is to defend that the song "Pra frente, Brasil", sung by Regina during the interview, functioned as a discursive event subtly integrated into an interdiscursive network that, in Brazil, continually reinforces symbolic recycling of historical memory referring to the period of the Military Dictatorship (1964-1985) by updating the discursive memory. In order to do so, based on key concepts within the theoretical and methodological framework of the French Discourse Analysis, a conceptual path is developed mainly based on the notions of historical memory, discursive memory, interdiscourse and pre-discourse.
\end{abstract}

Keywords: Historical memory. Discursive memory. Interdiscourse. Prediscourse.

Cadernos CESPUC de Pesquisa. Série Ensaios. n.37, $2^{\circ}$ Sem./2020, p. 126-146. e-ISSN: 2358-3231 (OJS). Recebido em: 16/og/2020. Aceito em: 19/10/2020. 


\section{Introdução}

Em tempos de crise, é comum que a esfera política vire palco oportuno de performances discursivas e que, sob holofotes ideológicos, narrativas dissonantes se digladiem em busca do arrebatamento do auditório, criando um revolto espetáculo do qual irrompem-se silenciamentos e ao qual ninguém presta ovações. Embora o avassalador cenário pandêmico que, em 2020, já vitimou centenas de milhares de pessoas ao redor do globo demande mais empatia e afetividade do que uma metáfora teatral como essa é capaz de oferecer, tudo indica que ela é lamentavelmente acurada para introduzir o objeto de análise deste artigo. Fato é que, em terras brasileiras, não bastasse a crise sanitária e as turbulências da esfera política, um recente episódio esdrúxulo profanou parte da memória histórica da política brasileira, dessa vez em forma de uma constrangedora pantomima. Em 7 de maio de 2020, o Brasil assistiu, perplexo, a ex-secretária especial de cultura, a atriz Regina Duarte, não apenas banalizar a letalidade do vírus Covid-19, mas também contribuir para uma simbólica reciclagem da já obscurecida memória histórica referente ao período da Ditadura Militar no país (1964-1985), durante uma entrevista concedida à emissora de televisão CNN Brasil. Em rede nacional, indagada sobre seus planos à frente do finado Ministério da Cultura - recentemente rebaixado à condição de Secretaria Especial - durante a pandemia, Regina garantiu que "onde há vida, há morte", confessou que preferia manter o "alto astral", cantarolou em tom saudosista e mungangueiro a canção "Pra frente, Brasil", repudiou o apelo de auxílio à classe artística feito em vídeo por Maitê Proença, sua ex-colega de trabalho, e, finalmente, sugeriu que havido sido emboscada pela emissora - que, de forma precoce e desconcertante, foi compelida a encerrar a lastimosa entrevista.

Evidentemente, o trágico espetáculo protagonizado por Regina potencialmente oferece numerosas pautas para análises discursivas e, não obstante, parece haver um latente denominador comum que comprime todas elas: a banalização da morte. De qualquer forma, importa para a análise que aqui se pretende desenvolver um tópico relativamente ofuscado que, como já foi dito, fere a memória histórica brasileira. Na verdade, é muito provável que Regina não tenha consciência de que uma fugaz pantomima 
presente em sua performance durante a entrevista jogou mais uma pá de cal sobre o túmulo em que jazem os mortos da Ditadura Militar. A canção "Pra frente, Brasil", criada em 1970 para incentivar um apoio ufanista à seleção brasileira de futebol na Copa do Mundo, mas que, na prática, serviu para desviar a atenção das severas violências impingidas pelo Estado, foi ressuscitada pela ex-secretária especial de cultura em tom saudosista para sugerir que os bons tempos haviam ficado para trás. Embora o entrevistador, visivelmente incomodado, tenha respeitosamente repreendido o argumento e sublinhado a letalidade daquele amargo período, o saudosismo de Regina apenas confirma a contínua e perigosa reciclagem de uma memória histórica que deveria ter sido há muito revisitada e passada à limpo, sobretudo em um país que se diz democrático. Entretanto, até os dias atuais, as únicas incursões legislativas bem-sucedidas foram as que se prestaram a impedir esta autópsia simbólica e, de fato, tudo indica que o ex-presidente João Figueiredo conseguiu selar de vez esse impedimento quando sancionou, ainda em 1979, a aviltante e imperdoável Lei da Anistia (BRASIL, 1979), a qual autorizou a impunidade e alavancou o esquecimento. Até mesmo Dilma Rousseff, que foi vítima de torturas no período, surpreendentemente acabou se esquivando de invalidar a famigerada lei quando ainda ocupava o posto da presidência da república. Portanto, parece justo tentar recuperar e esclarecer as estratégias que insistentemente promovem esta reciclagem memorialística e propor uma breve análise crítica sobre as nuances modernas de determinados discursos que, simbolicamente, continuam reforçando esquecimentos.

Para tanto, alguns conceitos caros à Análise do Discurso (doravante $\mathrm{AD}$ ) de base pecheutiana serão empregados neste texto na tentativa de esclarecer o funcionamento e as consequências da relação entre memória e discursividade. Pretende-se, com isso, desenvolver um mapeamento teórico-metodológico que dê conta de evidenciar como a pantomima de Regina é, na verdade, um acontecimento discursivo que faz parte de uma contínua e paciente rede interdiscursiva que, articulada por determinadas formações ideológicas, as quais ainda serão esclarecidas, recorrentemente recicla a memória histórica por meio da atualização da memória discursiva. Nessa perspectiva, as práticas comunicativas são concebidas como metonímias das relações de poder embutidas na esfera pública e o discurso torna-se um incansável gerador de consensos coercitivos que, em grande 
medida, impõem ideologias de modo velado e manobram o modo como os sujeitos experienciam e interpretam os fatos sociais. Sendo assim, a próxima seção desse texto se propõe a explorar o conceito de memória a partir das noções de acontecimento discursivo (PÊCHEUX, 1983), formação discursiva, interdiscurso, intradiscurso (FOUCAULT, 2008; PÊCHEUX, 1995, 1997; COURTINE, 2014) e memória discursiva (COURTINE, 2014), além de outros conceitos acessórios. Não obstante, pretende-se também considerar algumas valiosas contribuições de Marie-Anne Paveau (2013) que, ancoradas nas noções acima, consolidaram a ideia de pré-discurso. Todos estes conceitos servirão para construir um mapeamento apto a esclarecer como as lentes ideológicas filtram o olhar sobre a realidade e, discursivamente, são capazes de atualizar e apagar memórias.

\section{A memória e o esquecimento no discurso}

Em $\mathrm{AD}$, memória é um conceito que aparece de modo espraiado, disperso, ramificado em numerosos postulados edificados por autores que se prestaram a escrutinar o complexo funcionamento do discurso a partir da articulação entre o que é sócio-histórico e o que é linguístico. Talvez se possa dizer com grande segurança que memória é um domínio imanente em qualquer análise discursiva, afinal, as práticas comunicativas são sempre uma espécie de refração semântica, que desloca e atualiza sentidos outrora manifestos. Fato é que não há nada de novo debaixo do sol e todas as palavras já foram ditas, no entanto, temos sempre a impressão do inédito. Este curioso curto-circuito memorialístico ocorre porque o discurso é, segundo Pêcheux (1983), estrutura e acontecimento, de modo que o sentido de um enunciado é refém de uma operação interpretativa evanescente, passível de coloridos situacionais que reverberam nos sujeitos por meio das práticas comunicativas. Além disso, a opacidade intrínseca da linguagem impede que os sentidos se cristalizem e, portanto, o discurso torna-se um agenciador de possibilidades; em outros termos, a materialidade linguística é fadada ao equívoco, pois qualquer enunciado tem potencial para se tornar matéria-prima de novos acontecimentos discursivos. Um enunciado como "Pra frente, Brasil" é totalmente aberto a filtros interpretativos e 
pode ser usado em um sem-número de discursos; na verdade, cada vez que foi proferido, seja em 1970 ou em 2020, se tornou um acontecimento discursivo e, consequentemente, possibilitou interpretações distintas, pois rompeu a estabilidade de uma memória anterior - embora não a tenha apagado, apenas a ressignificado. Nesses termos, a noção de acontecimento discursivo faz da memória basicamente um paradoxo: é lembrança e é esquecimento - só assim se pode reivindicar o já-dito em nunca-dito.

Com efeito, pensar a atualização da memória por meio do esquecimento exige o auxílio de outros conceitos elementares à $\mathrm{AD}$, para que não se cofunda a memória histórica e a memória discursiva. Como já foi dito, no fim das contas entende-se que as práticas comunicativas são convites a movimentos interpretativos, pois fundamentam-se em um contínuo deslizamento de sentidos que se atualiza efetivamente no discurso. Mesmo assim, convém sublinhar que, segundo a AD francesa, este deslizamento não é aleatório e muito menos de competência dos sujeitos; é resultado da interseção entre interdiscurso e intradiscurso. Além disso, qualquer atualização semântica fomentada por acontecimentos discursivos está inscrita em uma rede de memórias autorizada por um conjunto complexo de formações discursivas. Entretanto, antes de mergulhar nas noções de interdiscurso e intradiscurso, importa considerar as relações de poder embutidas no conceito de formação discursiva e, dessa forma, fatalmente nos aproximamos da tese do assujeitamento.

Embora seja plausível estipular as intenções de um sujeito que, por meio do discurso, atualiza memórias, para a $\mathrm{AD}$ francesa não é isso o que acontece, pois nega-se a ideia de um essencialismo subjetivo e assume-se que a produção de sentido é um movimento impositivo. É nesse viés que Orlandi (2007) explica que, embora o sujeito se imagine como origem do que diz e pense ter autonomia na construção dos sentidos, ele, na verdade, se constitui sujeito na linguagem. Em outros termos, tudo o que o sujeito diz está circunscrito ao que ele "pode dizer", pois, segundo Pêcheux (1997 [1969]), o sujeito é interpelado pela ideologia e, dessa forma, o estatuto do sujeito se constrói na linguagem e independe das intenções do indivíduo. Soa, de fato, um tanto radical a tese do assujeitamento e a supressão da subjetividade sinaliza um notório ponto fraco dessa linha de pensamento - justamente por isso Pêcheux (1983 [1975]) acabou fazendo uma revisão conceitual, a fim de incluir tonalidades subjetivas no assujeitamento e, 
assim, insinuou uma articulação entre o inconsciente e a ideologia. Não obstante, em uma tentativa de absorver o contraditório, o divergente, previuse a estratificação deste assujeitamento e, para tanto, edificou-se a ideia de forma-sujeito, fracionada em graus de pertencimento, de identificação ideológica ${ }^{1}$. De um jeito ou de outro, a ideia por trás do assujeitamento é pertinente, pois visa projetar a ideologia e o discurso para o centro da produção de sentido e, com isso, o próprio sujeito torna-se uma espécie de efeito de sentido.

Diante desta logística deveras coercitiva, então, importa sublinhar os alicerces objetivos do assujeitamento e suas respectivas manifestações. $\mathrm{Na}$ verdade, apontou-se, mais acima, que o sujeito "diz o que pode dizer", e esta é uma das definições possíveis para o conceito de formação discursiva, de modo que o assujeitamento pode ser entendido como uma espécie de consequência operacional do discurso. Começa a se desenhar, assim, não apenas o conceito de formação discursiva, mas também o de interdiscurso e o de intradiscurso, que serão esclarecidos logo à frente e conduzirão à ideia de memória discursiva. De fato, embora o conceito de formação discursiva tenha paternidade compartilhada com Foucault (2008 [1969]), entendese que as reflexões de Pêcheux (1995) ancoraram de vez a prevalência da ideologia nas análises discursivas. Se Foucault, buscando compreender o funcionamento dos discursos que compõem as ciências humanas, se debruçou sobre um princípio de dispersão dos enunciados a fim de rastrear suas regularidades e, consequentemente, delimitar o que ele entendia por formação discursiva, Pêcheux se pautou nos estudos marxistas para apontar como o sujeito situa-se em uma incontornável luta de classes que condiciona o seu dizer; isto é, o lugar social que ele ocupa licencia aquilo que pode e deve ser dito. Nessa perspectiva, a formação discursiva é uma espécie de matriz de sentidos, vinculada a um conjunto complexo de atitudes, crenças e representações - as formações ideológicas - que orientam não apenas o modo como o sujeito se posiciona na luta de classes, mas, sobretudo, como ele produz sentido. Em outros termos, a formação discursiva pode ser entendida como manifestação da formação ideológica que condiciona os

\footnotetext{
1 Quem definiu de maneira clara a estratificação da forma-sujeito foi Freda Indursky (2000). Segundo a autora, quando o sujeito se identifica plenamente com a forma-sujeito implicada em uma formação discursiva dominante, tem-se um caso de superposição; quando o sujeito questiona e se distancia, o caso é de contraindentificação; finalmente, quando ele se desloca totalmente da forma-sujeito, ocorre a desidentificação e, consequentemente, uma espécie de migração para outra formação discursiva - ou seja, não é uma questão de "desassujeitamento", pois ele se identifica com outra formação discursiva que, igualmente, $\mathrm{o}$ assujeita.
} 
dizeres. Não obstante, falar em luta de classes é falar de atritos ideológicos e é justamente por isso que se compreende a produção de sentido como uma disputa coletiva que visa à construção de um consenso estável, o qual filtre a interpretação das experiências sociais e, na medida do possível, conduza o comportamento dos sujeitos. Trata-se, no fim das contas, de uma gestão sociopolítica.

Se, com efeito, na visão de Pêcheux, o sujeito é interpelado pela ideologia e, por meio do discurso, ele manifesta o seu grau de pertencimento e afiliação ideológica em meio à luta de classes, como seria possível reciclar os sentidos por meio de acontecimentos discursivos? Uma resposta para esse questionamento repousa sobre as noções de interdiscurso e intradiscurso. Tome-se, por exemplo, o conceito de "democracia". Um ditador enrustido pode perfeitamente engendrar uma atitude monocrática, argumentar que o faz em nome da democracia e persuadir numerosos devotos de que é exatamente isso que está fazendo; tal manobra é o reflexo da ideologia operando através de uma formação discursiva e transfigurando o já-dito - o que se sabe da democracia e o que já foi dito sobre ela. Nesses termos, foram cunhadas as ideias de interdiscurso e intradiscurso, que, segundo Indursky (2003), compõem uma espécie de plano cartesiano, de modo que o interdiscurso, no eixo vertical, compreende um conjunto de formações discursivas que articulam o que já foi dito e indiciam o encadeamento daquilo que é passível de ser repetido, enquanto o intradiscurso, no eixo horizontal, corresponde à prática discursiva do sujeito, a sua enunciação. $\mathrm{O}$ ponto de contato entre os eixos concretiza, então, o acontecimento discursivo que atualiza e projeta o pré-construído (o já-dito) no tempo presente - precisamente o que fez Regina; mas ainda não é hora de falar dela. Em outros termos, por compreender um conjunto de formações discursivas que, em grande medida, determina os possíveis deslocamentos de sentidos, o interdiscurso é heterogêneo e oferece a matéria-prima discursiva (o pré-construído) que será rearticulada em contato com o intradiscurso; nos termos de Pêcheux (1995, p. 167), o intradiscurso é um "efeito do interdiscurso sobre si mesmo". De fato, todas estas considerações insinuam a definição de memória discursiva defendida por Courtine (2014 [1981]), mas talvez seja oportuno retomar mais uma contribuição de Pêcheux antes disso, para que fique mais clara a distinção entre memória histórica e memória discursiva, que será extremamente útil à análise subsequente. 
Em 1983, por ocasião de um evento acadêmico realizado em Paris, intitulado Histoire et linguistique, Pêcheux participou, junto com outros pesquisadores, de uma mesa redonda ${ }^{2}$ cujo tema central era o papel da memória, sobretudo nos estudos da linguagem. Entre outras coisas, advogou-se que a memória é um entrecruzamento de sentidos - míticos, sociais, discursivos e, claro, históricos - e não deve ser encarada por um viés individualista. A ideia, com efeito, era a de esclarecer que memória não é um repositório de eventos, com bordas fixas e instransponíveis, mas uma rede volúvel e dialética de deslocamentos, de ressignificações, de contradiscursos, de disputas e (por que não?) de repetições. Aberta, portanto, a operações discursivas, entende-se que memória é eminentemente um território em disputa, ao qual ninguém pode reivindicar insuspeição. Nessa perspectiva, pode-se dizer, por exemplo, que qualquer tentativa de recuperar um fato histórico implica, em tese, reestabelecer uma série de implícitos acessórios e, assim, a memória histórica é reconfigurada por meio do discurso, que institui não apenas um deslocamento espaço-temporal, mas um deslocamento semântico materializado por práticas comunicativas. Ora, a ressignificação é um processo discursivo e, portanto, uma memória histórica, quando recuperada, é atravessada pela opacidade da linguagem e vira matéria-prima de acontecimentos discursivos. Foi pautado nestas operações que Courtine (2014 [1981]) consolidou, antecipadamente, a ideia de memória discursiva, a qual, em grande medida, se aproxima das noções de interdiscurso e de pré-construído, pois articula uma espécie de estatuto social da memória ancorado sobre o que é "real na história" e o que é "real na língua", ou seja, aquilo que é passível de ser repetido, refutado e transformado nas práticas discursivas que operam sobre o já-dito. Portanto, memória discursiva é praticamente uma disputa ideológica pela interpretação, na qual os sujeitos, por meio do intradiscurso, se apropriam da memória histórica e ecoam as vozes do interdiscurso.

A vulnerabilidade da memória histórica fica, com efeito, cristalina. A produção de sentido é obrigatoriamente um processo coletivo contínuo e mesmo que se consolide um consenso relativamente estável sobre um fato ou um período histórico específico - a exemplo da Ditadura Militar no Brasil - ele será sempre passível de reformulações. Nessa perspectiva, compreende-se que a ideologia é praticamente onipotente e que as práticas

2 As reflexões de Pêcheux nesta mesa redonda foram posteriormente publicadas por Achard et al. (1999). 
discursivas materializam a sua onipresença, mas talvez seja oportuno relativizar algumas nuances deste funcionamento e considerar brevemente pontuais considerações de Paveau (2013) antes de encerrar esta seção. Fato é que a linguista francesa não apenas revisitou o quadro teórico da $\mathrm{AD}$ pecheutiana, mas se propôs a inserir tonalidades cognitivas que são deveras atraentes. Em termos gerais, Paveau problematiza a imanência do assujeitamento ideológico e devolve certa autonomia às configurações socioculturais dos sujeitos - algo que, de fato, se mostra promissor, tendo em vista a incompletude da obra de Pêcheux em razão de sua morte precoce. Além disso, o viés cognitivista ${ }^{3}$, em diálogo com os postulados da $\mathrm{AD}$, joga luz sobre formas variadas de organização do discurso, incluindo, para isso, reflexões sobre artefatos e tecnologias que "distribuem" as matizes semânticas, tais como símbolos linguísticos, objetos manufaturados, obras arquitetônicas etc. Com efeito, Paveau define os pré-discursos como enquadres prévios de saberes, de crenças e de práticas que circulam em determinados grupos sociais, são acessíveis ao indivíduo pela cultura e, sobretudo, são distribuídos nos ambientes materiais das produções discursivas. Assim, a própria memória passa a ser uma espécie de operador pré-discursivo e, não obstante, novamente é possível enxergar grande proximidade com as noções de pré-construído e interdiscurso, mas fica claro que a autora confisca grande parte da onipotência atribuída às formações ideológicas e propõe uma espécie de fragmentação do poder social, que se manifesta na apropriação conjunta de certas crenças e conhecimentos pelos grupos sociais. A hipótese do assujeitamento, nesse viés, se fragmenta, mas sobrevive um caráter coercitivo das práticas discursivas, ainda que de modo relativizado e distribuído.

Evidentemente, esta brevíssima apresentação do conceito de prédiscurso está longe de esgotar a extensa pauta epistemológica esquadrinhada por Paveau ao longo de seu livro, que até hoje causa certa tensão entre analistas do discurso, independentemente de suas vertentes teóricas. $\mathrm{Na}$ verdade, todos os conceitos esboçados até aqui são apenas sucintos

\footnotetext{
3 Com o propósito de cunhar o conceito de pré-discurso, Paveau (2013) apresenta um extenso mapeamento da genealogia epistemológica da AD francesa e, ao mesmo tempo, promove um diálogo com as teorias cognitivas, com ênfase na tese da cognição distribuída, proposta originalmente por Hutchins (1995) e explorada por Conein (2004). A ideia central por trás dessa tese é a de se esquivar do internalismo cognitivo e explorar com mais amplitude o funcionamento da relação entre linguagem, memória e pensamento, a fim evidenciar como as operações cognitivas são influenciadas pelo ambiente cultural. Para tanto, buscou-se mostrar como as formas contemporâneas de produção e circulação dos discursos são distribuídas na sociedade não apenas nas práticas comunicativas, mas também em lugares, objetos, símbolos etc. Nesse viés, a memória discursiva é igualmente pautada em uma operação distribuída. Tudo isso ficará mais claro na próxima seção deste texto.
} 
mapeamentos teóricos considerados estratégicos para tratar da relação entre memória e discursividade, que será o pano de fundo para a análise discursiva subsequente. Dessa forma, os conceitos pinçados do quadro teórico da $\mathrm{AD}$ francesa com base em Pêcheux, aliados às contribuições de Paveau, servirão de lentes analíticas para a identificação dos mecanismos discursivos, sociais e ideológicos por trás da famigerada entrevista concedida pela ex-secretária especial de cultura e, de fato, a memória discursiva e os pré-discursos talvez sejam os conceitos mais elementares entre os que foram aqui sugeridos. No entanto, eles não são suficientes para a identificação das nuances ideológicas embutidas nas práticas sociais que coercitivamente impõem aos sujeitos uma interpretação parcialmente pré-determinada dos fatos; justamente por isso propôs-se o sucinto trajeto teórico apresentado. Sendo assim, está na hora de cruzar o Atlântico e retornar às terras brasileiras - aparentemente um palco inesgotável de peripécias discursivas.

\section{Brasil: palco inesgotável de peripécias discursivas}

A operacionalização discursiva mais costumeira que se faz da memória é a guerra de narrativas; até mesmo entre historiadores há conflitos - não à toa investiga-se a história da historiografia. Nesse sentido, como já ficou claro, um eventual consenso sobre a memória histórica passa obrigatoriamente pela memória discursiva e, por causa disso, disputas, reformulações e até apagamentos são inevitáveis. No Brasil, tudo indica que pouquíssimos - quiçá nenhum - períodos históricos são plenamente consensuais e o exemplo mais evidente disso é a Ditadura Militar, que, embora tenha durado 21 anos e deixado irremediáveis cicatrizes em uma geração inteira, é alvo de injuriosos saudosismos. Nem mesmo o minucioso e impactante relatório produzido pela Comissão Nacional da Verdade (BRASIL, 2014), dividido em três extensos volumes que juntos somam mais de 3.000 páginas, foi capaz de esclarecer ao povo brasileiro que aquele talvez tenha sido o período mais amargo, autoritário e violento desde a abolição da escravatura, em 1888. Diante disso, esta seção se propõe a tentar esclarecer o funcionamento dos mecanismos ideológicos, discursivos e simbólicos que são capazes de colocar em funcionamento este 
poderoso mecanismo de apagamento e reciclagem memorialística. Não obstante, pretende-se consolidar a hipótese de que a ex-secretária especial de cultura, Regina Duarte, ao cantarolar uma marchinha popular associada ao período da Ditadura durante sua constrangedora entrevista à emissora CNN Brasil ${ }^{4}$, em 7 de maio de 2020, promoveu, sem ter plena consciência disso, um acontecimento discursivo sintonizado a uma rede interdiscursiva que continuamente contribui para a reciclagem da memória histórica referente ao período da Ditadura Militar no Brasil (1964-1985), por meio da atualização da memória discursiva.

De fato, no início deste texto introduziu-se brevemente a peculiar entrevista de Regina e sublinhou-se que ela é um prato cheio para diversas análises discursivas. Nesse sentido, a partir do recorte selecionado para análise, é possível notar que a alusão saudosista ao período do regime militar está intimamente conectada a um discurso que banaliza a morte algo que se aproxima do conceito de necropolítica, estipulado pelo filósofo camaronês Achille Mbembe (2016), o qual dissertou sobre cenários em que o Estado se projeta como responsável pela jurisprudência da morte, por decidir quem tem o direito de viver e quem não tem, seja pela injunção, seja pela omissão. Ora, se a necropolítica explícita do regime militar torturava e matava seus opositores políticos, a necropolítica latente no discurso da ex-secretária especial de cultura se manifesta quando, diante da gravíssima pandemia do vírus Covid-19, que continua causando a morte do milhares de brasileiros, ela afirma que "[...] a humanidade não para de morrer, se você falar de vida, de um lado tem morte [...] A Covid está trazendo uma morbidez insuportável, não tá legal! (sic)". Sabe-se que, na época da entrevista, Regina era integrante do governo e, portanto, sua fala pode ser compreendida não apenas como uma banalização da morte, mas, sobretudo, como uma espécie de justificativa para a omissão - nesse caso específico, enquanto secretária especial de cultura, ela reforçou a sua omissão diante do apelo de auxílio à classe artística feito em vídeo por Maitê Proença e diante da morte de figuras importantes da cultura brasileira em virtude da pandemia, como a do músico Moraes Moreira e a do escritor e compositor Aldir Blanc. Sendo assim, embora o cenário pandêmico pelo qual passamos não seja pauta da presente análise, ele revela como o discurso de Regina tem as tonalidades da necropolítica e, ao mesmo tempo, sinaliza como a alusão

$4 \mathrm{O}$ vídeo integral da entrevista está disponível em: https://www.youtube.com/watch?v=v9gLHrP7RNw 
saudosista à Ditadura pode ser encarada como parte integrante da poderosa rede interdiscursiva de reciclagem e ressignificação da memória histórica, tendo em vista que a banalização da morte é uma característica de ambas.

De modo geral, entende-se que a entrevista de Regina é um belo exemplo da operacionalidade da memória discursiva e, não obstante, a marchinha confirma a tese de Paveau (2013), pois ilustra a "distribuição" dos operadores discursivos que dão acesso a certas crenças, saberes e representações, materializados não apenas por meio de práticas comunicativas, mas também de artefatos simbólicos. Fato é que, criada durante o período da Ditadura Militar para prestigiar a seleção brasileira na Copa de 70, que conquistou o tricampeonato e acalentou o coração de todos aqueles que, à época, não estavam nos porões dos militares, a marchinha ufanista "Pra frente, Brasil" foi cantarolada por Regina em tom saudosista e com saracoteios dignos de uma pantomima. É claro que pode-se dizer que a música em si é apenas um pequeno fragmento de memória e que talvez o seu traço mais distintivo seja, de fato, a alusão ao título futebolístico, mas é curioso que ela tenha sido evocada justamente quando a ex-secretária foi questionada sobre o seu alinhamento ideológico frente aos rumos da política no país. Também é curioso que, segundos antes de cantarolar a marchinha, Regina tenha dito que não pretendia ficar olhando para trás e reavivando memórias das décadas de 60, 70 e 80. É igualmente curioso que, logo em seguida, Regina tenha cantado a marchinha para rememorar o que, para ela, eram "os bons tempos". E é fatalmente curioso que o seu discurso se alinhe, como já foi dito, à necropolítica, que durante o regime militar era explícita, mas que hoje se dissimula em descaso e omissão. Na verdade, nada disso é curioso. Tudo isso são ramificações da rede interdiscursiva.

Entende-se que essa rede interdiscursiva teve longos anos de maturação e é composta por formações discursivas diversas que, via de regra, partilham nuances ideológicas. Não é novidade, por exemplo, que até os dias atuais há quem chame de "Revolução de 64" o golpe de Estado que destituiu Joao Goulart da presidência e iniciou a Ditadura no Brasil. Este é um belo exemplo da operacionalização da memória discursiva por meio de uma prática comunicativa, mas sublinhe-se, mais uma vez, que crenças, saberes e representações também se manifestam em outros operadores discursivos, como artefatos simbólicos. Recentemente, os Correios identificaram mais de 700 ruas no Brasil que foram nomeadas em homenagem aos 
protagonistas da Ditadura Militar, como se pode notar em uma matéria produzida pelo jornal O Globo ${ }^{5}$. Em contraste, houve diversas iniciativas de grupos e instituições ligadas a direitos humanos com o intuito de renomear estas ruas, no entanto, em muitos lugares, como em São Paulo, elas não foram bem-sucedidas. Tudo isso corresponde a uma espécie de guerra narrativa entre formações discursivas distintas, que disputam o consenso a respeito de uma memória histórica e, por isso, é possível rastrear as nuances ideológicas que se traduzem nas formações discursivas. Ora, quem se refere ao episódio de 64 como "Revolução" certamente é interpelado (para usar os termos de Pêcheux) por ideologias ultranacionalistas, conservadoristas e até militaristas - mesmo que, curiosamente, o termo "revolução" seja comumente associado a ideologias mais progressistas e socialistas; mais um caso de curto-circuito, dessa vez, no léxico. Esse tipo de disputa narrativa sem dúvidas é uma das ramificações do que se nomeou aqui de rede interdiscursiva.

Não obstante, nota-se que desde a crise político-econômica iniciada em 2013 no Brasil uma pungente polaridade ideológica acentuou a guerra pelo consenso a respeito do período do regime militar e, não à toa, foi justamente nessa época que, valendo-se dos direitos democráticos que, ironicamente, só foram instituídos com o fim da Ditadura, uma parcela significativa dos brasileiros começou a pedir, amiúde, intervenção militar, fechamento das instituições democráticas e até restauração do AI-5, o ato mais violento da época, que suprimiu quase todos os direitos civis dos brasileiros. Aparentemente, isso são aberrações ininteligíveis, mas, no fim das contas, são apenas reflexos da amplitude da rede interdiscursiva que continuamente promove a reciclagem desta memória histórica no país. A fim de explorarmos um pouco mais as formações ideológicas constituintes desta disputa narrativa, é oportuno fazer uma brevíssima digressão ao ano de 2013, pois, como foi sugerido acima, nesse época o saudosismo da Ditadura definitivamente ampliou seus adeptos. Depois de mais de uma década de um governo de centro-esquerda, que acumula méritos e deméritos, uma incipiente recessão econômica tornou-se gatilho para o desenvolvimento de uma veemente campanha antigovernista, a qual adquiriu cores conservadoristas e "antissocialistas" quase instantaneamente. Nasceu, assim, o antipetismo, caracterizado por discursos inflamados não apenas contra o

5 Ver: https://oglobo.globo.com/brasil/brasil-tem-727-logradouros-que-homenageiam-presidentes-militares-12032700. 
Partido dos Trabalhadores (PT), mas, sobretudo, contra as ideologias mais à esquerda, que se enxergaram em uma espécie de cruzada cuja missão era a de defender a nação contra a famigerada "ameaça comunista" - um termo que visivelmente é uma herança histórica, pois foi precisamente essa a tese usada para destituir João Goulart, em 1964. Evidentemente, seria improdutivo realizar uma extensa e minuciosa análise de conjuntura sobre todos os acontecimentos que, de 2013 aos dias atuais, materializam a demonização das formações ideológicas mais sintonizadas ao socialismo. $\mathrm{O}$ que nos importa aqui, quando se recupera esse período, é ilustrar uma fase considerada de extrema importância na contínua disputa discursiva que reivindica o consenso sobre a memória histórica e, sendo assim, nota-se que as formações discursivas vinculadas a formações ideológicas conservadorase ultranacionalistas, que flertam com o militarismo, lograram um significativo êxito que se reflete, por exemplo, nas manifestações que hoje pedem uma nova intervenção militar ${ }^{6}$. Esse êxito é tão grande que, nos dias atuais, em alguma medida, até mesmo grupos sociais cujas formações ideológicas são divergentes têm se aproximado; neoliberais moderados e progressistas de centro-esquerda, por exemplo, têm percebido a necessidade de defender pautas comuns que são elementares, como a preservação da divisão entre os três poderes, que incrivelmente vem sendo cada vez mais ameaçada, tendo em vista que as mesmas manifestações que pedem o retorno dos militares pedem igualmente o fechamento do Congresso Nacional.

Nesses termos, entende-se que a rede interdiscursiva que recorrentemente atualiza a memória histórica da Ditadura Militar tem ampliado não somente a sua capilaridade, mas, sobretudo, a sua eficiência. Dessa forma, o Brasil tem presenciado a ascensão de uma formação discursiva com características ideológicas ultranacionalistas e monocráticas e, para tanto, diversos artifícios foram e continuam sendo utilizados. Ora, há muitos indícios disso, mas, se levarmos em consideração apenas os que foram até aqui apontados, é possível enxergar até mesmo uma espécie de encadeamento simbólico-discursivo, que se inicia no termo "Revolução de 64", se alastra nos mais de 700 nomes de ruas que homenageiam presidentes militares, ganha força com o nascimento do antipetismo construído em 2013 (o qual enxerga o "comunismo" em tudo que não seja a sua própria

6 Nos últimos anos, as manifestações que pedem a volta dos militares têm ocorrido em várias partes do país, como fica claro no vídeo divulgado pela "Revista Sociedade Militar": https:/www.sociedademilitar.com.br/2020/04/pedidos-de-intervencao-militar-retornam-com-forca-no-paismanifestacoes-em-varios-locais-do-pais-pedem-abertura-em-niteroi-en toaram-hinos-militares.html 
formação ideológica) e, nos últimos anos, tem se traduzido na forma de contínuos pedidos de intervenção militar e de fechamento das instituições democráticas. Dentro desse quadro, entende-se que a pantomima de Regina também é um singelo adendo a esta rede interdiscursiva e representa mais uma operacionalização da memória discursiva, pois a marchinha foi usada como um gatilho memorialístico que ativa um equivocado saudosismo pelos "bons e velhos tempos". Não obstante, antes de encerrar esta seção e apresentar as considerações finais, vale a pena passar um pente fino em um último aspecto simbólico relevante para a análise, a fim consolidar a hipótese de que a entrevista faz parte desta rede interdiscursiva.

É possível que, em virtude do constrangimento causado pela performance da ex-secretária especial de cultura, tenham passado despercebidos os dois quadros que compõem o cenário da entrevista, assinados por Rubem Valentim, um artista brasileiro que é referência do construtivismo brasileiro. Extremamente peculiares e geométricos, os quadros são uma releitura de símbolos das religiões indígenas e afrobrasileiras e foram doados ao finado Ministério da Cultura - hoje Secretaria Especial de Cultura - em 2004, quando Gilberto Gil estava à frente do órgão. O que é relevante para a análise é que, embora os quadros simbolizem a pluralidade cultural, identitária e religiosa do nosso país, eles acabaram sofrendo uma espécie de curto-circuito simbólico, se considerarmos que a entrevista faz parte de uma rede interdiscursiva que, na contramão da função social da arte e da cultura, recicla memórias históricas e silencia a pluralidade identitária, religiosa e, claro, ideológica. Dois episódios recentes podem encorpar esta hipótese. O primeiro deles é que, em janeiro de 2020, o antecessor de Regina, Roberto Alvim, publicou um vídeo ${ }^{7}$ nos canais oficiais do governo para garantir que, daquele momento em diante, a arte brasileira seria "heroica, nacional e imperativa". Imediatamente a declaração foi vista como paráfrase de uma fala de Joseph Goebbels, ministro de propaganda do governo nazista. O segundo episódio importante é que em uma reunião ministerial realizada em abril deste ano ${ }^{8}$, cuja gravação se tornou de domínio público, o ex-ministro da educação, Abraham Weintraub, afirmou que odiava os termos "povos indígenas" e "povos ciganos", e que o Brasil deveria ser um povo só, homogêneo. Entende-se que, juntos, os três episódios -

\footnotetext{
7 O vídeo foi apagado pela SECOM, mas continua disponível em: https://www.youtube.com/watch?v=3lycKFW6ZHQ

8 A transcrição integral da reunião ministerial pode ser acessada em: https://issuu.com/mnnovaes/docs/laudo_digitalizado
} 
o vídeo de Alvim, a declaração de Weintraub e a entrevista de Regina ajudam a construir a imagem de que cultura e educação são ferramentas nacionalistas homogeneizantes.

\section{FIGURA 1: Regina Duarte, em entrevista à CNN Brasil.}

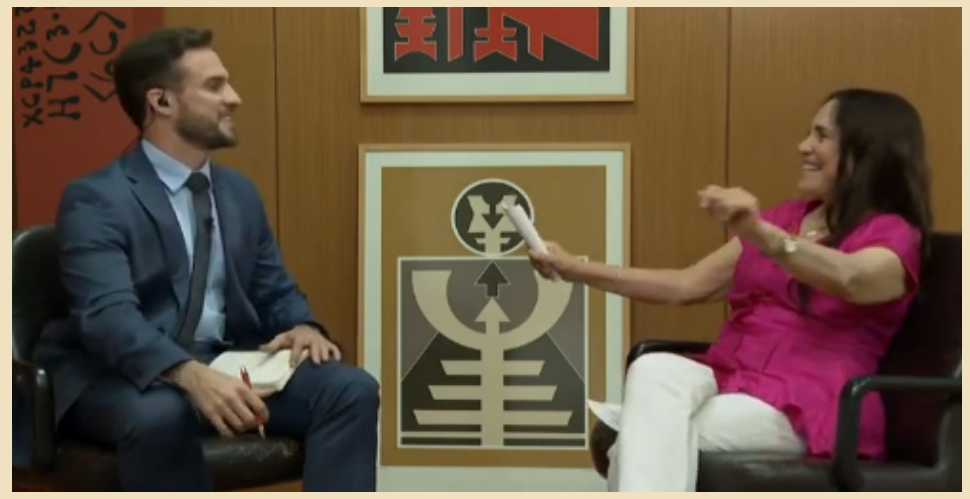

Fonte: Revista Fórum, 2020

Este exemplo relativamente periférico, com efeito, engrossa a hipótese de que uma rede interdiscursiva de apagamento e reciclagem da memória histórica tem ampla capilaridade no cenário brasileiro e pode se manifestar em suportes e artefatos variados, pois compreende-se que os quadros de Rubem Valentim sofreram um curto-circuito simbólico ao servirem de suporte cenográfico para um acontecimento discursivo que, entre outras coisas, se vincula à ideologia ultranacionalista que tem ganhado notoriedade nos últimos anos. Há, de fato, muitas outras ramificações e implicações desse viés ideológico que não foram contempladas neste texto, as quais podem ser percebidas, por exemplo, quando propõe-se que seja comemorado o aniversário do golpe de 64 ou quando a Câmara dos Deputados precisa emitir um parecer técnico ${ }^{9}$ para explicar que o artigo 142 da Constituição de 88 não pode ser usado como pretexto para validar uma intervenção militar. Exemplos desse tipo são numerosos nos dias atuais, mas seria inviável analisá-los todos aqui. De qualquer forma, tudo o que já foi dito parece consolidar a ideia de que essa rede interdiscursiva é ampla, distribuída e visivelmente eficaz, pois cada vez mais o discurso

\footnotetext{
9 Em junho de 2020, época de intensas rusgas entre os poderes constitucionais, aventou-se a possibilidade de que o artigo 142 da Constituição poderia ser usado para "restaurar a ordem" no país, fato que obrigou a Câmara dos Deputados a publicar o seguinte parecer técnico: https://www.camara.leg.br/ midias/file/2020/06/parecer.pdf/.
} 
ultranacionalista se apoia na reciclagem da memória histórica para expandir seus territórios e convencer grande parte da população brasileira de que uma nova versão do regime militar é a única opção para combater a famigerada "ameaça comunista". Sendo assim, importa agora encerrar a análise e apresentar as considerações finais.

\section{Considerações finais}

Diante da breve análise aqui proposta, entende-se que a pandemia do vírus Covid-19 não é a única enfermidade que aflige o Brasil nos dias atuais. Tudo indica que a nossa jovem e inexperiente democracia padece de uma vulnerabilidade memorialística que põe na berlinda a sua própria existência. Por isso, o objetivo deste texto foi deslindar uma espécie de empreitada ideológico-discursiva que é distribuída em práticas sociais e artefatos simbólicos, ora de modo sutil, ora de modo explícito. Nessa perspectiva, o objeto de análise selecionado - a fugaz pantomima de Regina, que imprimiu a uma marchinha vinculada ao período da Ditadura um tom faceiro e saudosista - é uma das sutis ramificações do que se chamou aqui de uma rede interdiscursiva que continuamente recicla a memória histórica por meio da atualização da memória discursiva. Dessa forma, os conceitos pinçados do quadro teórico da $\mathrm{AD}$ francesa de base pecheutiana, além das contribuições de Paveau (2013), foram utilizados com o propósito de esclarecer os mecanismos discursivos e as nuances ideológicas que promovem o funcionamento dessa rede e, em grande medida, exercem notável influência não apenas sobre o comportamento dos sujeitos, mas também sobre a logística da política brasileira, que segue flertando com impulsos militaristas e antidemocráticos. Sob a batuta de uma formação ideológica ultranacionalista, a esfera política tem sido palco de discursos coercitivos e ameaçadores que constroem a ideia de que é necessário, pela força, combater um "velho inimigo comum": o comunismo - o qual, atualmente, já virou uma pecha atribuída a todos aqueles que discordam, em maior ou menor grau, deste viés ideológico ultranacionalista e militarista. Marx deve se revolver no túmulo quando acusam um neoliberal convicto, como o governador de São Paulo, João Dória, de ser comunista. 
Portanto, nesse cenário no qual se propagam discursos ultranacionalistas que ameaçam as instituições democráticas, a pantomima da ex-secretária especial de cultura, performada durante a entrevista concedida à CNN Brasil em maio deste ano, é entendida como um acontecimento discursivo sutilmente integrado à rede interdiscursiva que operacionaliza a reciclagem da memória histórica referente ao período da Ditadura, e Regina sequer tem consciência disso, pois, em consonância a Pêcheux, ela é interpelada por uma formação ideológica que a assujeita e a faz contribuir para a atualização da memória discursiva, assim como fazem os milhares de manifestantes que clamam por uma intervenção militar e pela dissolução dos três poderes - a última fronteira da democracia. Dessa forma, entende-se que a esfera política brasileira, especialmente a partir de 2013, tornou-se palco de disputas ideológicas polarizadas, que reivindicam um consenso não apenas sobre a memória de tempos passados, mas também sobre a memória do tempo presente. Ora, até mesmo a pandemia do vírus Covid-19 tem sido explorada por discursos político-ideológicos; a gestão da aparentemente dicotômica relação entre saúde e economia é uma pauta recorrentemente utilizada para contrastar formações discursivas e ideológicas. Aqueles que defendem a quarentena são vistos como "esquerdistas" e aqueles que defendem a reabertura econômica são vistos como "direitistas" - como se o conceito de ideologia fosse, de fato, binário. Nesse ínterim, os grupos sociais menos privilegiados continuam enterrando os seus mortos e a necropolítica moderna continua se esquivando de combater as mazelas sociais. Em suma, compreende-se que a memória do tempo presente está em plena construção, alicerçada sobre contínuas reciclagens memorialísticas a serviço de uma rede interdiscursiva cujas formações ideológicas são, no mínimo, alarmantes.

\section{Referências}

BRASIL. Comissão Nacional da Verdade. Mortos e desaparecidos políticos / Comissão Nacional da Verdade. Brasília: CNV, 2014. 
BRASIL. Lei $\mathrm{n}^{\circ} \mathbf{6 . 6 8 3}$, de 28 de agosto de 1979. Concede a anistia e dá outras providências. Planalto, Brasília, 1979. Disponível em: <http://www. planalto.gov.br/ccivil_03/leis/L6683.htm>. Acesso em: 13 jul. 2020.

CNN BRASIL. Exclusivo: Regina Duarte minimiza ditadura e interrompe entrevista à CNN. 2020. (40m24s). Disponível em: <https://www.youtube. com/watch?v=v9gLHrP7RNw>. Acesso em: 16 jul. 2020.

CONEIN, B. Cognition distribuée, groupe social et technologie cognitive. Réseaux, v. 124, n. 2, 2004, p. 53-79.

COURTINE, J-J. Análise do discurso político: o discurso comunista endereçado aos cristãos. São Carlos: EDUFSCAR, 2014 [1981].

FOUCAULT, M. A arqueologia do saber. 7 ed. Rio de Janeiro: Forense Universitária, 2008.

HUTCHINS, E. Cognition in the wild. Cambridge, Massachusetts: MIT Press, 1995.

INDURSKY, F. A fragmentação do sujeito em análise do discurso. Em: INDURSKY, F.; CAMPOS, M. C. (org.). Discurso, memória e identidade. Porto Alegre: Editora Sagra Luzzatto, 2000, p. 70-81.

INDURSKY, F. Lula lá: estrutura e acontecimento. Organon. Porto Alegre: UFRGS, v. 17, n. 35, 2003, p. 101-121.

MBEMBE, A. Necropolítica. Arte \& Ensaios. Rio de Janeiro: UFRJ, v. 32, n.2, 2016. Disponível em: <https://revistas.ufrj.br/index.php/ae/article/ view/8993>. Acesso em 16 jul. 2020.

ORLANDI, E. P. A questão do assujeitamento: um caso de determinação histórica. ComCiência. Campinas: LABJOR-UNICAMP, n. 89, 2007.

PAVEAU, M-A. Os pré-discursos: sentido, memória, cognição. Campinas: Pontes, 2013.

PÊCHEUX, M. Discurso: estrutura ou acontecimento. Campinas: Pontes, 1983. 
PÊCHEUX, M. Semântica e discurso: uma crítica à afirmação do óbvio. 2 ed. Campinas: Edunicamp, 1995 [1975].

PÊCHEUX, M. Análise automática do discurso (AAD-69). Em: HAK, T.; GADET, F. (org.). Por uma análise automática do discurso: uma introdução à obra de Michel Pêcheux. 3. ed. Campinas: Edunicamp, 1997 [1969], p. 61-105.

PÊCHEUX, M. O papel da memória. Em: ACHARD, P. et al. Papel da memória. Campinas: Pontes, 1999, p. 43-52.

REGINA Duarte é abandonada por aliados da classe artística após entrevista à CNN. Revista Fórum, [s.l.], 11 maio 2020. Disponível em: <https:// revistaforum.com.br/cultura/regina-duarte-e-abandonada-por-aliadosda-classe-artistica-apos-entrevista-a-cnn/>. Acesso em: 16 jul. 2020. 